\title{
Marketing resource management: A hype or a must have?
}

\begin{abstract}
Atilla Kerpisci
has more than 15 years of experience in Marketing, Business Development, Account Management and e-Consultancy. As a business consultant (eg at KPN and others), he translated various business and marketing objectives in different sectors (Utilities, Industry, Public, Agricultural, IT and Retail) into functional, organizational and technical solutions, especially in the area of telecommunications, e-Business, and Brand and Identity Management. As a Director e-Services with NykampNyboer - Managing Visual Performance - , he is now responsible for the portfolio, marketing and sales of all e-solutions in the area of brand management, marketing operations and print management solutions. (NykampNyboer, a Dutch-based company, is a market leader in visual identity implementation and management. The activities and services of NykampNyboer consist of project and process management, consultancy and integrated solutions, to help customers implement and managing their identity, brand and to apply it consistently and correctly in all corporate and marketing communications. In the 16 years existence, a wide portfolio of national and international customers make use of the NykampNyboer services, such as Heineken, Corus, Starbucks, ABN AMRO, Randstad, etc.)
\end{abstract}

Keywords: systems, logistics, traffic, MRM, brand, measurement

Abstract Is marketing resource management (MRM) a hype or a must-have? It is certain you have come across references to MRM before. MRM adds to your means of marketing communication and allows the full integration of a variety of marketing processes, but also beware of the pitfalls and fairytales.

Journal of Digital Asset Management (2007) 3, 99-101. doi:10.1057/palgrave.dam.3650065

\section{THE WAY TO GAINING TIME}

A new category of marketing technology software is emerging, designed to help you in increasing both efficiency and effectiveness of your marketing resources. It is called marketing resource management (MRM). MRM is the instrument that allegedly makes you spend considerably less time on planning, creation, production, execution and measurement. The reason behind it is that MRM adds to your means of marketing communication and allows the integration of a variety of marketing processes.

The time thus saved can be spent on the development of your brand and on determining your optimum marketing strategy: the alpha and omega of a superior brand.

After all the software system development NykampNyboer Olympisch Stadion 6 Amsterdam $1076 \mathrm{DE}$, The Netherlands Tel: +31 (0)541530900 Mobile: + $31(0) 62124$ 6752

Fax: + 31 (0)541530307 E-mail: a.kerpisci@ nykampnyboer.com Web: www.

nykampnyboer.com efforts in the field of Production, Finances and Logistics, Marketing now has its turn. Software companies have marked it as their new hunting ground and are now eagerly jumping on. Also, the well-established software companies are seizing the opportunity to bring a new life to their "old" software packages.

\section{Offerings difficult to compare}

In short, the marketing machine for "marketing machines" is doing overtime.

All kinds of new concepts and their subsequent abbreviations are flooding the market. It is certain that you have come across references to MRM, marketing operations management (MOM), enterprise marketing management (EMM) and marketing supply chain management before.

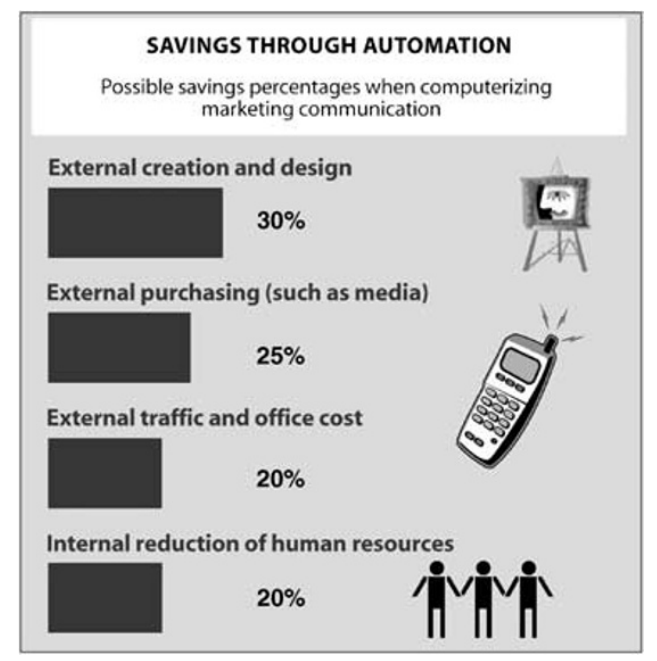




\section{In one blow}

It is difficult to determine what concept suits your organization and your users best, mainly because you must start with a clear insight in the process or the discipline that you really want to improve on. Your hesitation about which path to follow is not strange because many software companies adhere to the marketing strategy of hitting as many flies in one blow as possible. It is difficult to compare and see through the variety of offers. Fortunately, all software suppliers have one thing in common: yet again they are promoting their system as the sheer magic to solve all the problems that you may have come across - an eternal trap. Focusing on the real problem that you may have is apparently too much to ask for. But it is almost certain that you well remember that many a techno push has more often than not led to costly and long implementations, with the sad result of the organization donning its own straight jacket, diligently following the software program's demands as opposed to the program being supportive of one's own working methods and processes.

\section{Chaos}

All this goes without saying that in the fields of marketing governance and marketing communication quite a bit of catching up still needs to be done. Chaos prevails in the way many businesses have organized their marketing operations:

- No or non-transparent processes around brand and brand application;

- Strong dependency on many third parties: advertising agencies, media planners, buyers, printers etc;

- Little campaign coordination, insight or integrated marketing communication planning;

- Brand exposure elements, know-how and visual identity components scattered over the company, third parties, or stored in various applications or software systems, whereby visual elements are more often than not out of date or in the wrong formats;

- Expenditure on unnecessary advertising, DTP and design, wasting time and money;

- Totally inadequate campaign measuring; Hardly any or no insight in cost versus effectiveness.

And to cap it all often "own" systems are deployed, such as the odd spreadsheet or document. Needless to say that this information is not accessible to all and valuable knowledge is lost when a member of staff decides to leave the company.

Also, adding more channels to the marketing communication mix makes the coordinated marketing effort more difficult. Doesn't it drive you up the wall when the brochure still needs printing and the e-zine still needs to be sent while the brand new make of car is already in your showroom?

The deadline prevails in the land of marketing. Apparently, nobody is counting the cost when the safeguarding and the meeting of deadlines are at stake - if only the work is done properly and on time, both bad excuses to justify a waste of money.

\section{ONE PRACTICAL OVERVIEW: RE-USE}

But can creativity be computerized? True, you can't actually "catch" real creativity, but all the fuss and bother around it most certainly can be organized. The processes involved can very well be standardized and subsequently be computerized.

It brings you a lot. Inefficient management makes your company dependent on others and causes traceable and hidden costs. Also, a lot can be gained from the reuse of templates, photos and other media material.

Planning your own campaign or advertising, personalizing, producing and maintaining your own marketing efforts yourself, with no dependency on external parties leads to less traffic and less external DTP and buying costs.

When introducing new brands or with extensive re-branding operations, it greatly helps to have one overall view (read: database) comprising all current visual identity carriers, brand and marketing assets. Tools with which to work on these in order to simply and quickly convert them into the new visual identity or brand expression obviously need to be included.

Most of the MRM software packages include one or more of these features.

\section{Privileges}

The human factor, however, should not be neglected. Tools are but a means. If you change processes and procedures, you are changing your marketers' way of working and their other 
"privileges." Probably, the computerization of operations will lead to less human effort, which enables your staff to concentrate on other matters.

Marketing is and will ever remain humans' work. So both at the initial implementation of the MRM system and at its daily use the following critical factors need to be observed:

\section{During implementation:}

- From day one, include your users in the project setup. What are their needs and how do they work?

- Organize a supportive attitude of the various disciplines within your organization. Why not take the product or IT manager out to a business lunch?

- Look for MRM references. What do other marketers say about the system?

- Count the cost. What are you spending now, how effective is it? What are you going to do with the extra available resources?

- Start on a surveyable small scale.

2. During deployment:

- Ensure loyalty within the user group. Use incentives or loyalty programmes for instance to reward use.

- Launch new functionality and features of the MRM system on a regular basis, promote the interactivity of the system and make it fun to work with.
- Avoid "big brother is watching you" sentiments, in spite of the fact that the MRM system has many built-in checks and report features.

- Always guard the user friendliness. Take suggestions and complaints seriously.

\section{CLEVER ORGANIZATION AND LOGISTICS: SEAMLESS}

Once you are able to see through the MRM hype, you will certainly find meaningful ways to test your own marketing activity on logistics and market effectiveness. If well introduced and implemented MRM may provide considerable added value to the strategic, tactical and operational marketing process.

In many cases, the solutions will contribute to a cleverer organization and logistics setup of the marketing supply chain, will add more grip, overview and measurability. The marketing activity can be better judged on its merits and it is easier to account for investments made; in other words, better accountability of your marketing is the harvest you will reap.

In the future, however, MRM will (have to) be further integrated with Sales, CRM and Business Intelligence, so that in time it supports the whole cycle from marketing strategy up to sales and service. These processes and activities eventually need to be connected seamlessly, yielding information and other revenues that make every Euro you spend on marketing an extremely well-spent one. 